Jurnal Care Vol. 4, No.3, Tahun 2016

\title{
PEMBERDAYAAN PEDAGANG PASAR TRADISIONAL BLIMBING BERBASIS PARTISIPATIF DALAM PERLINDUNGAN SOSIAL
}

\author{
Lasri $^{1)}$; Novita Dewi ${ }^{2)}$, Budi Prihatiningtyas ${ }^{3)}$ \\ ${ }^{1,2,3)}$ Universitas Tribhuwana Tunggadewi Malang \\ e-mail:mrs.lasri1956@gmail.com
}

\begin{abstract}
Every human beings need clothing, shelter, food, love \& affection and also actualization. The traditional market traders are traders who have high expectations and confidence that will be successful in meeting the needs of both health and living needs for their children and or families, especially the well being and health. The study was aiming to determine the empowerment of Blimbing traditional market traders based participatory in social protection. This was a qualitative research study with a participatory approach. The sample of 253 people are taken using stratified random sampling which are divided into three groups: 95 greengrocers, 80 fruit sellers, as well as 78 traders staple. Collecting data by questionnaires, interviews and observation. The findings showed that as many as 55 (21.8\%) staple traders from Malang Raya; most of the 53 (20.9\%) greengrocers are elementary education; 105 (41.5\%) of 20-35-year-old trader; as many as 158 people (62.5\%) had no BPJS cards and as many as 49 people (19.36\%) often have dermatitis. It takes the role of community health centers, government, higher education and active community participation in the management and use of the cards BPJS / JAMKESMAS for the merchant market.
\end{abstract}

Keywords: traditional market traders, social protection

\section{ABSTRAK}

Setiap manusia membutuhkan sandang, papan, pangan, cinta kasih \& sayang dan aktualisasi.Kelompok pedagang pasar tradisional merupakan sekompok pedagang yang mempunyai harapan tinggi, serta keyakinan tinggi bahwa akan berhasil untuk memenuhi kebutuhan baik kesehatan maupun kebutuhan hidup anaknya, keluarganya terutama dalam kesejahteraan dan kesehatannya. Tujuan penelitian ini adalah untuk mengetahui pemberdayaan pedagang pasar tradisional Blimbing berbasis partisipatif dalam perlindungan sosial. Penelitian ini merupakan penelitian kualitatif dengan pendekatan partisipasif. Sampel sebanyak 253 orang diambil dengan teknik stratified random sampling yang terbagi dalam tiga kelompok yakni 95 pedagang sayur, sebanyak 80 pedagang buah, serta 78 pedagang kebutuhan pokok. Pengumpulan data dengan kuesioner, wawancara dan observasi.Hasil temuan didapatkan bahwa sebanyak 55(21,8\%) pedagang bahan pokok berasal dari Malang Raya; sebagian besar yakni 53(20,9\%)pedagang sayur berpendidikan SD ; sebanyak 105(41,5\%)pedagang berusia 20-35 tahun;sebanyak158 orang(62,5\%) tidak mempunyai kartu BPJS dan sebanyak 49 orang (19,36\%) sering mengalami dermatitis. Dibutuhkan peran puskesmas, pemerintah, Perguruan Tinggi dan partisipatif aktif masyarakat dalam pengurusan dan penggunaan kartu BPJS/JAMKESMAS bagi pedagang pasar.

Kata kunci: Pedagang pasar tradisional, perlindungan sosial 


\section{PENDAHULUAN}

Setiap manusia dituntut untuk memenuhi kebutuhan hidup kesejahteraan, kesehatannya dan bisa memenuhi kebutuhan pokok yang menyangkut kelangsungan hidup anak dan keluarga. Dalam melaksanakan pekerjaannya, tidak jarang pedagang merasakan kondisi tubuh yang tidak sehat/cenderung sakit dan harus memeriksakan diri ke pelayanan kesehatan. harapan para pedagang tentunya sempurna jasmani rohani serta mendapatkan pelayanan kesehatan sesuai peraturan yang ada.

Dunia kerja dan dunia kesehatan ,bagi pedagang cenderung dijadikan tiang harapan yang lebih menjanjikan untuk mencukupi kebutuhan sandang,papan, pangan ,nyaman,aman (kebutuhan fisik) dan cinta kasih sayang, aktualisasi diri(kebutuhan psikologis). Walaupun banyak bermunculan toko dan swalayan namun keberadaan pasar tradisional tetap diminati oleh pembeli lokal maupun dari berbagai daerah.Hal ini yang membuat para pedagang pasar tradisional tetap berkerja. Pedagang pasar tradisional mayoritas berdagang pada malam hari sehingga harus tekun, sabar terampil ,serta menerima kondisi pekerjaannya. Adanya keterpaksaan untuk masuk dunia kerja yang tidak diimbangi dengan pengetahuan dan pengalaman yang cukup , bahkan dengan kemampuan ,keahlian yang terbatas. Hal tersebut menyebabkan rentannya kesehatan pedagang.Padahal jika di lihat dari jumlah pedagang tradisional, bisa dikategorikan sebagai sumber daya manusia yang jumlahnya besar sehingga menyerap tenaga kerja. Pekerjaan sebagai pedagang di pasar dilakukan sepanjang hari mulai pagi hari sampai dengan malam hari, praktis selama 24 jam berada di pasar. Pedagang pasar dapat dibedakan menjadi beberapa kelompok antara lain pedagang menjual kebutuhan pokok,pedagang buah dan pedagang menjual sayur, berbagai kebutuhan .

Peranan pedagang di pasar tradisional cukup tinggi antara lain memiliki peran penting dalam upaya peningkatan pendapatan keluarga, selain itu juga tentunya menjaga kesehatan keluarga dan dirinya,namun pada kenyataanya kurang mendapatkan perhatian baik dari bidang kesehatan, maupun pemerintah.Adanya anggapan pula bahwa masyarakat pedagang tradisional mempunyai kedudukan yang rendah. Ketidaktauan dalam mengurus fasilitas Badan Penyelenggara Jaminan Sosial ( BPJS) BPJS, tidak adanya waktu dalam mengurus BPJS,rendah nya kesejahteraan,kesadaran, 
partisipasi serta fungsi kontrol membuat para pedagang pasar tradisional semakin tertinggal. Pedagang pasar tradisional pada umumnya kurang mengenali keselamatan yang mengancam dirinya, kurang memahami aturan-aturan tempat bekerja,kurang mengenali kekuatan dan kelemahan sendiri, serta kurang berani dalam mengemukakan pendapat. Hal ini terjadi dikarenakan tidak tersedianya jaminan sosial secara formal dan perlindungan sosial (Sukesi,dkk 2010) bagi pedagang di pasar tradisional. Perlunya ada kebijakan yang kondusif, berhubungan dengan pengurusan perlindungan sosial dan kesehatan bagi sektor terkait dengan pedagang di pasar tradisional.

\section{METODE PENELITIAN}

Penelitian ini menggunakan metode kualitatif dengan pendekatan partisipatif. Pelaksanaan penelitian bertempat di Pasar Blimbing Malang. Sampel dalam penelitian ini berjumlah 235 pedagang diambil dengan stratified random sampling sehingga didapatkan 3 kelompok pedagang yakni 95 pedagang sayur, sebanyak 80 pedagang buah serta 78 pedagang kebutuhan pokok. Kriteria inklusi sampel adalah telah berjualan lebih dari 2 tahun. Pengumpulan data dengan menggunakan kuesioner, wawancara serta observasi dengan mengambil beberapa elemen. Masing-masing elemen diselidiki secara mendalam, untuk memperoleh informasi tentang profil pedagang pasar tradisional blimbing.

\section{HASIL}

Berdasarkan pengelompokkan jenis dagangan diketahui bahwa dari 253 pedagang didapatkan sebagian besar pedagang sayur 95(37,5\%), pedagang buah $80(31,6 \%)$ dan pedagang bahan pokok sebanyak $78(30,8 \%)$.

Dari Tabel 1 diketahui bahwa sebagian besar didomisili oleh pedagang bahan pokok $55(21,8 \%)$ dari Malang raya dan 50(19,7\%) dari luar Malang.

Dari Tabel 2 diketahui bahwa sebagian besar pedagang sayur berpendidikan SD yakni sebanyak 53 orang(20,9\%); sebanyak $35(15 \%)$ pedagang buah berpendidikan SMA; dan sebanyak $35(13,8 \%)$ pedagang bahan pokok berpendidikan SMA.

Dari Tabel 3 diketahui bahwa sebagian besar pedagang berusia 20-35 tahun yakni $105(41,5 \%)$. 
Jurnal Care Vol. 4, No.3, Tahun 2016

Tabel 1. Distribusi Frekuensi Berdasarkan Domisili Pedagang di Pasar Blimbing Malang

\begin{tabular}{lcccc}
\hline Kelompok pedagang & Malang raya & Luar malang & jumlah & $(\%)$ \\
\hline Pedagang sayur & $30(11,8 \%)$ & $40(11,8 \%)$ & 70 & $15,8 \%$ \\
Pedagang buah & $43(16,9 \%)$ & $35(13,8 \%)$ & 78 & $30,8 \%$ \\
Pedagang bahan pokok & $55(21,8 \%)$ & $50(19,7 \%)$ & 105 & $41,5 \%$ \\
\hline Total & $128(50,6 \%)$ & $125(49,4)$ & 253 & $100 \%$ \\
\hline
\end{tabular}

Tabel 2.Distribusi Frekuensi Berdasarkan Pendidikan Terakhir Pedagang di Pasar Blimbing Malang

\begin{tabular}{|c|c|c|c|}
\hline Kelompok padagang & Pendidikan terakhir & Jumlah & $(\%)$ \\
\hline \multirow[t]{4}{*}{ Pedagang sayur } & a.SD & 53 & 20,9 \\
\hline & b.SMP & 32 & 12,6 \\
\hline & c.SMA & 10 & 3,9 \\
\hline & d. Perguruan Tinggi & 0 & 0 \\
\hline \multirow[t]{4}{*}{ Pedagang Buah } & a.SD & 15 & 5,9 \\
\hline & b.SMP & 27 & 10,6 \\
\hline & c. SMA & 35 & 15 \\
\hline & d.Perguruan Tinggi & 3 & 1,2 \\
\hline \multirow[t]{5}{*}{ Pedagang Bahan Pokok } & a.SD & 20 & 7,9 \\
\hline & b.SMP & 10 & 3,9 \\
\hline & c. SMA & 35 & 13,8 \\
\hline & d.Perguruan Tinggi & 13 & 5,2 \\
\hline & & 253 & 100 \\
\hline
\end{tabular}

Tabel 3. Distribusi Frekuensi Responden Berdasarkan Usia Pedagang di Pasar Blimbing Malang

\begin{tabular}{|c|c|c|}
\hline Usia(thn) & Jumlah & $\%$ \\
\hline $20-35$ & 105 & 41,5 \\
\hline $36-50$ & 83 & 32,8 \\
\hline $51-60$ & 49 & 19,4 \\
\hline $61-70$ & 16 & 6,3 \\
\hline Total & 253 & 100 \\
\hline
\end{tabular}

Dari Tabel 4 diketahui bahwa sebagian besar pedagang belum mempunyai kartu BPJS yakni sebanyak 158 orang $(62,5 \%)$ dan sebagian tersebar dalam kepemilikan kartu BPJS, Jamkesmas serta askes yang dimiliki oleh isteri Pegawai Negeri Sipil(PNS)
Tabel 4. Distribusi Frekuensi Pedagang Berdasarkan Kepemilikan Kartu Kesehatan di Pasar Blimbing Malang

\begin{tabular}{lcc}
\hline Kepemilikan & Jumlah & $\%$ \\
\hline Kartu BPJS & 45 & 17,7 \\
Jamkesmas & 10 & 3,9 \\
Askes (Istri PNS) & 40 & 15,8 \\
Belum punya & 158 & 62,5 \\
BPJS & & \\
\hline \multicolumn{1}{c}{ Total } & 253 & 100 \\
\hline
\end{tabular}

Hasil wawancara dengan pedagang terkait partisipasi kesehatan yakni sebanyak $60 \%$ pedagang pribadi membeli obat bebas jika mereka sakit sebanyak $40 \%$ pergi ke layanan kesehatan. 
Tabel 5. Distribusi Responden Berdasarkan Jenis Penyakit Pedagang Pasar Tadisional Blimbing Kota Malang

\begin{tabular}{lcc}
\hline Jenis penyakit & Jumlah & $\%$ \\
\hline Dermatitis & 49 & 19,36 \\
Scabies & 32 & 12,64 \\
Insomnia & 30 & 11,9 \\
Hipertensi & 29 & 11,4 \\
Asma/sesak nafas & 25 & 9,88 \\
Diabites Militus & 22 & 8,69 \\
Kecelakaan & 20 & 7,90 \\
perjalanan & & \\
Kecemasan & 19 & 7,50 \\
ISPA & 19 & 7,50 \\
Sakit perut & 8 & 3,16 \\
\hline Total & 253 & 100 \\
\hline Sumber : Data Dinkes dan Puskesmas \\
\multicolumn{2}{l}{ Wilayah Malang 2015 (diolah) }
\end{tabular}

\section{PEMBAHASAN}

Sebagian besar pedagang adalah pedagang bahan pokok 55 (21,8\%) dari Malang raya dan 50(19,7\%) dari luar Malang. Dari sudut pandang keselamatan pedagang, untuk pedagang yang berasal dari Luar Malang sangat beresiko untuk mengalami kecelakaan. Berdasarkan hasil wawancara dengan pedagang disampaikan bahwa mereka menggunakan jasa ojek dan angkutan umum saat malam hari menuju Pasar Blimbing. Mereka berjualan 24 jam dimulai malam hari sampai dengan sore hari setiap harinya. Selain keselamatan juga berdampak pada kerentanan terhadap penyakit.Dibutuhkan stamina yang tinggi pada pedagang. Para pedagang juga sangat kurang mendapatkan informasi dan peluang dalam meningkatkan kesejahteraan, penyadaran serta perlindungan sosial.

Sebagian besar pedagang sayur berpendidikan SD yakni sebanyak 53 orang(20,9\%); sebanyak 35(15\%) pedagang buah berpendidikan SMA; dan sebanyak 35(13,8\%) pedagang bahan pokok berpendidikan SMA.Faktor pendidikan menjadi salah satu faktor yang menyebabkan rendahnya sudut pandang pedagang terkait kesehatan dirinya.Rendahnya pendidikan menyebabkan rendahnya kedudukan pedagang serta berdampak sangat luas yakni selain kesehatan juga kesejahteraan,partisipasi dan fungsi kontrolnya yang rendah.

Berdasarkan hasil penelitian sebagian besar responden berusia $20-35$ Tahun. Usia rentang 20-35 tahun merupakan usia produktif, sehingga dimungkinkan masih mengalami proses kehamilan dan keluarga berencana. Hasil wawancara disampaikan bahwa adanya harapan besar Pedagang untuk mempunyai kartu BPJS/ Jamkesmas, sehingga dapat membantu diri dan keluarganya dalam mendapatkan pelayanan kesehatan secara gratis. Selain rentang umur di atas, juga terdapat rentang umur yang lain yakni 36- 50 tahun sebanyak 83(32\%), antara 51- 60 
tahun sebanyak 49 (19,4\%), dan diatas 61-70 $\operatorname{tahun}(6,3 \%)$ Usia yang bervariasi,namun sama sama mendekati usia lansia menyebabkan mereka beresiko tinggi terhadap penyakit, sehingga mudah terserang penyakit (mengalami degeneratif). Aktivitas dagang yang padat setiap harinya yakni mulai jam 2 pagi sampai dengan sore hari jam 16.00, disertai tidak dapat beristirahat selama berdagang menyebabkan resiko penyakit juga semakin tinggi. Perilaku pedagang lainnya yang sudah menjadi sebuah kebiasaan adalah membeli obat bebas di kios pasar.Jika dikaji lebih lanjut, konsumsi obat bebas di usia yang semakin mendekati lansia akan memberikan dampak lain dari obat bebas tersebut.

Berdasarkan hasil penelitian penyakit yang sering dialami, sepuluh penyakit besar yang sering dialami pedagang pasar tradisional pasar blimbing adalah : dermatitis ,scabies,insomnia ,hipertensi/ darah tinggi,asma/sesak nafas, diabetes melitus,kecelakaan perjalanan,kecemasan ,ISPA,dan sakit perut. Adanya renovasi di Pasar Belimbing disertai dengan musim penghujan, menyebabkan lingkungan Pasar Blimbing kotor dan becek. Para pedagang banyak berjualan di bawah karena tidak mempunyai kios sendiri.
Sehingga banyak pedagang yang terjangkit penyakit lain seperti gatal, ISPA dll. Adanya penyakit yang diderita pedagang sangat berpengaruh terhadap stamina pedagang dalam mencari penghasilan.Komunikasi Informasi dan Edukasi(KIE) dari puskesmas wilayah kepada para pedagang dilakukan hanya satu kali yakni jika terjadi kasus KLB.

Belum semua pedagang Pasar Blimbing memiliki kartu BPJS. Sebanyak 158 orang $(62,5 \%)$ belum punya Kartu BPJS dengan alasan karena tidak mengetahui cara mengurusnya dan merasa belum membutuhkan saat ini. Sebanyak 45 orang $(17,7 \%)$ telah memiliki BPJS dan sebanyak 10 orang(3,9\%)telah memiliki jamkesmas, sebanyak 40 orang ( 15,8\%) yang berprofesi sebagai pedagang kebutuhan pokok telah memiliki askes ( dikarenakan isteri PNS).Dengan bantuan tim peneliti sebanyak 25 orang $(10 \%)$ telah mempunyai BPJS dan sebanyak 75 orang $(29,6 \%)$ masih dalam proses pengurusan. Adanya hambatan yang dihadapi peneliti saat membantu pengurusan BPJS pedagang yakni persyaratan berkas yang belum lengkap seperti KTP, Kartu keluarga, surat keterangan RT,RW, Kelurahan dan kecamatan yang harus sesuai domisili pedagang (di luar Kota Malang). 
Pemberdayaan pedagang pasar dimulai dari pemeriksaan kesehatan meliputi pengukuran tanda vital, pengukuran tekanan darah,asam urat,kolesterol dan gula darah.Hasil pemeriksaan kesehatan dievaluasi dan dilakukan rujukan ke pelayanan kesehatan untuk dilakukan pengobatan. Evaluasi dan dirujuk ke pelayanan kesehatan sampai dengan pengobatan.Upaya lain dalam pemberdayaan yakni gerakan partisipasi kelompok oleh ketua komunitas terhadap peningkatan ksehatan dan kesejahteraan.Peneliti berkoordinasi dengan kepala dinas pasar dan kepala pasar untuk mengumpulkan 3 kelompok komunitas yakni komunitas pedagang sayur, komunitas pedagang buah dan komunitas pedagang bahan pokok. Setiap komunitas diketuai oleh satu ketua kelompok dan wakil. Kegiatan berupa KIE tentang manfaat kartu BPJS dan Jamkesmas terhadap pelayanan kesehatan. Selain itu peneliti juga menjembatani kepengurusan kartu BPJS ke kantor BPJS.Serta kerja sama dengan Puskesmas Wilayah dan Dinas Pasar untuk membentuk Poskesmas di Pasar agar pedagang pasar tidak mengobati sendiri dan bisa mendapatkan pelayanan sesuai standar kesehatan dasar.

\section{KESIMPULAN}

Penelitian Pemberdayaan pedagang pasar Tradisional Blimbing berbasis Partisipatif perlindungan sosial di Kota Malang .adalah :

1. Pedagang pasar dikelompokan menjadi 3 kelompok, yakni pedagang sayur\& buah dan kebutuhan pokok, dipimpin oleh ketua sesuai komunitasnya

2. Kegiatan kepengurusan kartu BPJS, Jamkesmas hanya pada sebagian kecil pedagang. Sebanyak 158 pedagang belum memiliki kartu BPJS/Jamkesmas dikarenakan ketidak lengkapan berkas persyaratan kepengurusan.

3. Terjalinnya kerja sama dengan Puskesmas Wilayah dan Dinas Pasar untuk membentuk Poskesmas di Pasar agar pedagang pasar tidak mengobati sendiri penyakitnya dan bisa mendapatkan pelayanan sesuai standar kesehatan dasar.

4. Kegiatan komunikasi, informasi, edukasi kesehatan dilakukan melalui penyuluhan pada masyarakat pedagang Pasar Blimbing

Dibutuhkan peran puskesmas, pemerintah, Perguruan Tinggi dan partisipatif aktif masyarakat dalam pengurusan dan penggunaan kartu 
BPJS/JAMKESMAS bagi pedagang pasar.

\section{REFERENSI}

Depkes RI. (2010).Profil kesehatan Indonesia 2010 Menuju Indonesia sehat. Departemen Kesehatan RI: Jakarta.
Depkes RI. (2013).Profil kesehatan Indonesia 2013 Menuju Indonesia sehat. Departemen Kesehatan RI: Jakarta.

Prihatiningtyas,B.( 2010). Analisis faktor faktor yang berpengaruh terbadap kinerja usaha kecil di pedagang pasar kota Malang. Disertasi, Universitas Merdeka ,Malang. 